\title{
IMAGINARIOS APOCALÍPTICOS E INFANCIA EN LAS NOVELAS EN VOZ BAJA DE ALEJANDRA COSTAMAGNA Y LA EDAD DEL PERRO DE LEONARDO SANHUEZA
}

Apocalyptic imaginaries and infancy in the novels En voz baja, by Alejandra Costamagna and La edad del perro, by Leonardo Sanhuez

CRISTIAN MONTES CAPÓ

Universidad de Chile cmontes@vtr.net

Para gran parte de la crítica literaria chilena, como para el público lector en general, es elocuente la persistencia del imaginario dictatorial en la narrativa chilena de estas primeras dos décadas del siglo XXI. A pesar de que han transcurrido veinticinco años desde que se reconquistó la democracia, dicho imaginario parece seguir fortaleciéndose y reactualizándose. Esta situación adquiere particular importancia al tener en cuenta un corpus narrativo publicado entre el 2000 y 2014, conformado por escritores nacidos entre 1970 y 1990. Se está ante una producción literaria que ha sido definida como "novela de los hijos", entendiendo por ello una novela escrita por los hijos de quienes fueron víctimas directas de la dictadura, una narrativa donde se articulan de otra manera los temas de la memoria, el duelo y el trauma ${ }^{1}$. Se está ante escrituras compuestas por "restos, ruinas, faltas, fallos, equívocos (y) callejones sin salida (...) incomparecencias, (...) rebeldías y necesidades; voces narrativas que (...) se exponen (básicamente) desde la falla y desde una falta constitutiva que es la vivencia de la catástrofe" (Botinelli, 2016, p. 13-14).

Los escritores de "segunda generación", como también ha sido nombrada, poseen nítida conciencia de no haber sido, a diferencia de sus padres, protagonistas directos de la historia, pero sienten que sí fueron afectados, aunque de forma diferente a sus antecesores generacionales. Son textos que evidencian una carencia constitutiva en la que se perciben las huellas de una catástrofe. La percepción generalizada respecto de sus padres es que estos no pudieron cumplir sus expectativas y ello les dejó a los hijos una sensación de orfandad. Según Sergio Rojas (2015):

\footnotetext{
${ }^{1}$ Es interesante destacar que este fenómeno se observa también y de manera profusa en Argentina, donde la narrativa de los hijos muestra claras coincidencias temáticas y formales con lo que se está escribiendo en Chile en torno al tema. Por ello no es extraño que una de las más acabadas descripciones de las características de la escritura de los hijos en Argentina, sea absolutamente pertinente para caracterizar la producción narrativa chilena: "No solo cabe recalcar que su experiencia del pasado es radicalmente diferente, también se escribe desde otra temporalidad: ya no predomina de manera absoluta la memoria, sino que se enfoca el pasado desde las necesidades vitales del presente y desde el anhelo de poder ingresar en la dimensión del futuro. Al gesto deconstructor de relatos colectivos y familiares, del relato identitario mismo, le sigue una propuesta de reconstrucción precaria y fragmentaria, armada a base de la voz narrativa subjetiva" (Logie, 2015, p. 98).
} 
En sentido estricto no estamos ante la literatura de una generación, sino ante la literatura de los hijos de una generación, y entonces se escribe desde esa condición, la de los hijos, a los que les fue arrebatada la posibilidad de la novela (...) Pero los hijos no escribirán la novela de los padres porque ella consiste en el modo en que la historia era vivida en el cotidiano de ese presente hoy pasado, $\mathrm{y}$ ahora el hijo ha venido pura lucidez desterrada (p. 241).

Ello incide, como señala Lorena Amaro (2014), en que muchos de los escritos "estén signados por la culpa, una marca ineludible de su relación con el tiempo histórico y familiar. Esta culpa se debe a haber vivido la época infantil (...) bajo la violencia y crueldad de la dictadura pinochetista y haberse mantenido como niños que eran, ajenos a los giros políticos" (p. 38). Es elocuente que muchas novelas se focalicen en la infancia de los narradores-personajes, con el fin de procesarla y reelaborarla según la especificidad de cada experiencia personal ${ }^{2}$. El discurso infantil adquiere así la posibilidad de alcanzar una consistencia y legitimidad que la sociedad generalmente no le reconoce. Como plantea Andrea Jeftanovich (2012): "Tal vez en la ficción se da este espacio que hace posible el lugar de la infancia fuera de los determinantes de la familia, la escuela o el mercado que pretende fijarlas" (p. 31). Es el caso de En voz baja (1996) de Alejandra Costamagna, y La edad del perro (2014) de Leonardo Sanhueza, novelas que serán motivo de análisis en el presente trabajo, no solo por la condición de infantes de los narradores, sino porque a pesar de la distancia temporal entre ambas publicaciones, se observa la persistencia de un imaginario apocalíptico.

\section{IMAGINARIO SOCIAL Y SENTIMIENTO APOCALÍPTICO}

Como se mencionó anteriormente, un núcleo de significación relevante de esta producción narrativa de los hijos es la tendencia a seguir inscrita en el imaginario de la dictadura. Una investigación exhaustiva de este corpus exigiría, por tanto, tratar de develar en qué consiste esa especie de cerco significante con el que el ejercicio imaginativo se estrella, quedando atrapado en dicho imaginario. Una eventual hipótesis al respecto es que la persistencia temática tiene íntima ligazón con las formas en que esta textualidad ha procesado la experiencia colectiva del duelo y los efectos del trauma generado por la debacle simbólica que significó el golpe militar y los años de represión en Chile ${ }^{3}$. El ideologema de la dictadura alcanza en esta narrativa el estatus de un

\footnotetext{
${ }^{2}$ Según Rubí Carreño (2009), una de las principales subjetividades que se despliegan en el nuevo siglo son las novelas de memorias juveniles. Estas articulan un discurso fictivo sobre el pasado dictatorial y lo hacen "desde una percepción de infancia o juvenil" (p. 24).

${ }^{3}$ El concepto de debacle simbólica remite a una amplia gama de significados, que remite, en este caso, tanto a los crímenes de la dictadura como a la ruptura del tejido social. Según Carla Peñaloza (2015): "Sabemos que uno de los objetivos fundacionales de la dictadura era eliminar a sus opositores (...) y para ello organizó sus tropas y procedió a la ejecución o desaparición forzada de personas desde el primer día. La idea era acabar con las organizaciones sociales y políticas que durante años habían fortalecido la política nacional, ya fueran de distintas veredas, pero en una convivencia democrática que rápidamente fue destruida. La pérdida fue de vidas humanas, pero también de espacios de construcción y participación sociales, públicas e ideológicas”' (p. 213).
} 
imaginario social, aludiendo con ello a un mecanismo en donde un grupo humano elabora una representación de sí mismo, define sus relaciones con los otros, conserva y modela el pasado y proyecta sus temores y esperanzas al futuro (Baczko, 1984, p. 2830). El estudio del imaginario social de estas "memorias narrativas", que según Elizabeth Jelin (2002) "pueden encontrar o construir los sentidos del pasado y las heridas de la memoria" (p. 27-28), posibilita entender en qué consiste la fidelidad al trauma. Ello podría revelar, en parte, una reticencia o deseo inconsciente de no desprenderse de este ni del proceso de duelo constante.

Puede afirmarse, por tanto, que en el imaginario social de esta generación se encuentra activado un sustrato apocalíptico íntimamente ligado al proceso de duelo que la escritura postdictatorial viene desarrollando desde el momento en que la democracia fue recuperada. Ello no se vincula, sin embargo, a una matriz religiosa donde sea posible visualizar una iluminación futura o una cierta redención. Lo que se advierte, en cambio, en el modo que tienen los escritores de reconocerse al rememorar el pasado, es un generalizado sentimiento de desesperanza y una sensación de apocalipsis sostenido que articula pasado, presente y futuro y se experimenta como una sensación de catástrofe constante. Es un tipo de apocalipsis que se expresa más bien en un tono apocalíptico, el que no supone directamente la presencia de un evento terminal al modo de una iluminación posterior a la crisis generalizada. Según Klaus Sherpe, las versiones posmodernas del apocalipsis se caracterizan por desdramatizar la tradición apocalíptica, al desechar cualquier esperanza de renovación. Son escrituras que se concentran más bien en el aspecto catastrófico y no en un supuesto fin de la historia, revelando así una fascinación por estar en el borde de un final que nunca llega. El tono apocalíptico puede existir fuera de las narrativas redentoras y vivirse como una especie de Apocalipsis sin Apocalipsis, sin una propuesta de verdad última, es decir, como un final sin final, como un fin que nunca cesa (Sherpe, 1987, p. 95-96).

Por otro lado, este tipo de sentimiento apocalíptico laico y contrateleológico se define por el temor inconsciente de que en el futuro vuelva a producirse el suceso traumático y altamente doloroso. Al reflexionar acerca de este aspecto del trauma, Derrida, en una entrevista realizada por Giovanna Borradori, en su libro La filosofia en una época de terror-Diálogos con Jurgen Habermas y Jacques Derrida, señala que:

(...) la herida permanece abierta por el terror ante el porvenir, no solamente ante el pasado (...) La prueba que nos hace sufrir el acontecimiento tiene como correlato trágico, no lo que pasa actualmente o lo que pasó en el pasado, sino el signo precursor de lo que amenaza con pasar. El porvenir es quien determina lo inapropiado del acontecimiento, no el presente ni el pasado. O, por lo menos, si son el presente o el pasado, será solamente en tanto lleven sobre su cuerpo el signo terrible de lo que podría o podrá suceder, y que será peor de lo que haya sucedido jamás (...) Se trata de un trauma y, por consiguiente, de un acontecimiento cuya temporalidad no procede del ahora ni del presente pasado, sino de un impresentable que está por venir" (Borradori, 2004 ,p. 145). 
Las reflexiones de Sherpe y Derrida son productivas para los efectos de entender el sustrato apocalíptico inscrito en la representación de mundo de las novelas de los hijos. La idea del miedo inconsciente, pero imperante, de que vuelva a ocurrir una hecatombe como en el pasado, ha desembocado, según afirma Tomás Moulian (2010), en que "la sociedad chilena ha quedado mareada con el miedo que vuelve" (p. 60-61). Desde su perspectiva, además de la búsqueda de justicia se hace imperativo que las fuerzas armadas reconozcan, como institución, su responsabilidad en los crímenes, torturas y desaparecimientos cometidos durante la dictadura militar. Solo así podrá desvanecerse el temor a que la historia vuelva a repetirse: "Creo que falta y que es necesaria, porque sería la única (la institución militar) que puede calmar ese temor difuso de la repetición que está en el subconsciente" (p. 61).

Por esas razones, se considera aquí que la incorporación del término apocalipsis, para referirse a estas narrativas de los hijos, funciona como un significante privilegiado que revela una particular percepción de lo ocurrido en tiempos de dictadura, vale decir los crímenes atroces en contra de quienes pensaban distinto, las desapariciones, el miedo generalizado, la crisis de confianza y del sentido de pertenencia, la pulverización de toda utopía y la apabullante inserción en el neoliberalismo triunfante. El tono apocalíptico alcanzará justamente una particular expresión en los relatos de infancia, donde los narradores niños elaboran sus relatos moldeados por un imaginario terminal y concluyente, como puede apreciarse en La edad del perro de Leonardo Sanhueza y En voz baja de Alejandra Costamagna.

El sentimiento apocalíptico se vincula directamente a la experiencia del duelo que se ha venido gestando en tiempos de postdictadura, lo que conduce de manera natural a la oposición freudiana entre duelo y melancolía ${ }^{4}$. En este sentido, así como pueden advertirse características que se asocian a determinadas forma de procesar el duelo, se aprecia igualmente en esta escritura la inscripción de síntomas de melancolía, que se evidencian en la desencantada tonalidad anímica presente en los textos, en la precaria autoestima de los narradores y personajes y en un cierto anquilosamiento conductual para liberarse del estado negativo que los afecta.

La condición melancólica puede entenderse como una forma de respuesta a la experiencia traumática del pasado y como una manera de relacionarse tanto con este como con el futuro. Judith Butler, quien reelabora la dualidad freudiana duelo y melancolía, plantea que toda pérdida importante genera en los seres humanos un sentimiento de vulnerabilidad. Sufrir un duelo implica que el sujeto acepte que ha habido un cambio importante en su interior y que algo ha desaparecido para siempre. Tal

\footnotetext{
${ }^{4}$ Es importante recordar que Freud, en su célebre ensayo Duelo y melancolía (1917), sostiene que el trabajo del duelo se desarrolla en el transcurso de tres etapas: recordar, repetir y elaborar. Estas etapas permiten, de una manera positiva y liberadora, la integración de lo perdido. En caso contrario, es decir, en una experiencia de pérdida que no logre elaborarse por medio del trabajo del duelo, tal imposibilidad conduce ineludiblemente a la melancolía. El sujeto se identifica entonces con el objeto perdido, lo introyecta y se niega posteriormente a reconocer y aceptar dicha pérdida (Freud, 1978, p. 35-255).
} 
carencia, sin embargo, no siempre es procesada de modo constructivo, ni genera nuevas expectativas de futuro (Butler, 2006, p. 70). En el caso de la narrativa de los hijos ese algo siempre difuso y la aceptación de una pérdida de por sí incomprensible, no implica el cese del duelo ni la superación del estado de ánimo generalizado. Oscilando entre la posibilidad del duelo y el sentimiento melancólico, el tono apocalíptico parece advertir que la experiencia del duelo prolongado hasta hoy puede llegar a ser un proceso interminable.

Esta compleja sintomatología de época donde memoria, trauma, duelo y sentimiento apocalíptico se funden en el imaginario narrativo de esta producción novelística, revela en definitiva un estado de ánimo, entendiendo por ello la tonalidad emocional, no solo personal, sino social, que según Hans Ulrich Gumbrecht está siempre presente en todo texto literario. Tratando superar las limitaciones que observa en la deconstrución y los Estudios Culturales, Gumbrecht (2011) propone una tercera ontología de la literatura, esto es, "que los intérpretes e historiadores contemporáneos analicen y lean los textos literarios centrándose en las Stimmungen, estados de ánimo o tonalidades" (p. 12). Respecto de la operatividad del concepto de estado de ánimo, afirma que: "Un ensayo centrado en los estados de ánimo no develará la verdad contenida en el texto, pero al menos nos hará comprender el texto como parte vital del presente" (p. 30).

Coincidiendo con Gumbrecht en cuanto a que todo texto literario genera determinadas sensaciones y revela un estado de ánimo de un período histórico, es posible plantear que en estas novelas de los hijos la sensación anímica que se advierte es que en el pasado ocurrió una catástrofe de alguna manera definitiva e irrevocable. Y ello tiene una conexión profunda con el sentimiento melancólico generalizado y el sustrato apocalíptico inscrito en el orden de la representación. Lo anterior adquiere una particular connotación en novelas donde los narradores pertenecen al mundo de la infancia.

\section{LOS TEXTOS: DOLOR, SILENCIO, MEMORIA}

A nivel del discurso de los hechos, la trama narrativa de En voz baja de Alejandra Costamagna se concentra en la experiencia de Amanda, protagonista y narradora de la historia, quien, en tiempos de dictadura, siente la necesidad de averiguar qué pasó con su padre, a quien dejó de ver abruptamente. Por ser un activista de izquierda, este debió exiliarse fuera del país y ello lo ha transformado en un tema vedado en las conversaciones familiares, como ocurre en la casa con cualquier tema relativo al contexto político del país. A pesar de ello, Amanda comenzará a indagar no solo en las razones que obligaron a su padre a dejar el país y su familia, sino también en los motivos que llevaron a la desarticulación familiar. Logrará finalmente su objetivo y podrá cerciorarse del cúmulo de traiciones de las que fue víctima su padre y de las peregrinas razones acerca del pacto de silencio en el que se habían comprometido los adultos, silencio que, según Amanda, fue expresión del engaño y la mentira a la que fue sometida durante todo el tiempo. Al sentir que todo a su alrededor es decepción y que no hay un verdadero sentido para seguir viviendo, Amanda desea morir. 
En cuanto a La edad del perro (2014), la novela se ambienta en 1983 (la primera parte) y en 1984 (la segunda parte), es decir, en plena época de dictadura. Quien narra tanto en tiempo presente ("Estoy sobre el techo de mi casa, en cuclillas") como en pasado, es un niño de nueve años que cuenta su historia familiar, en la ciudad de Temuco, desde situaciones domésticas como ayudar a su abuelo y excarabinero a arreglar el techo de la casa, acompañarlo a comprar un animal, recibir su primera bicicleta de regalo, etcétera, a otros aspectos como el divorcio de sus padres, la posterior ausencia de este, el incendio de la casa familiar poco después del golpe militar y el progresivo conocimiento respecto de lo sucedido con su padre, mecánico aéreo y sargento de aviación, y con la desaparición de personas en el contexto de la dictadura. El relato del niño estará cruzado por constantes alusiones a un supuesto fin de mundo donde ya se evidencian signos de destrucción generalizada, un tipo de apocalipsis que el personaje advierte desde una conciencia moldeada por las creencias de su abuela adventista.

Las homologías de significado más evidentes que se pueden observar entre ambas novelas, además de la presencia de narradores infantiles en pleno contexto dictatorial, son la ausencia del padre y su posterior muerte, la consecuente desarticulación familiar, la dualidad memoria/olvido, representada en la oposición: niños /adultos y la preponderancia de lo íntimo y familiar como epicentro fundamental del recuerdo y desde el que se convoca los acontecimientos que conforman la macrohistoria. En consecuencia con lo anterior, el proceso de reelaboración de la memoria privilegia la subjetividad como vía de expresión de una experiencia íntima y personal, ajena a toda forma de institucionalidad. El resultado de ello es un conjunto de representaciones que exponen "a través del territorio de lo íntimo los efectos devastadores sobre los sujetos de la política y de la ideología, en particular, cuando se vinculan al ideologema familiar y al mundo privado" (Llanos, 2013, p. 141).

En el caso de En voz baja, los personajes comprometidos en la historia narrada reactualizan en sus conductas y elecciones vitales la oposición memoria-olvido. En concordancia con ello se dividen en dos grupos claramente identificables. Por un lado están la narradora Amanda y su hermana Virginia, quienes desean conocer qué pasó verdaderamente con su padre y con su amigo Roberto, y por otro el mundo de los adultos, representados espacialmente por la madre de Amanda y su actual pareja. ${ }^{5}$

Lo que se impone finalmente es el silencio ante los temas cruciales, como la ausencia del padre y el desaparecimiento definitivo de Roberto ${ }^{6}$. Como dice Amanda

\footnotetext{
${ }^{5}$ Según plantea Claudia Martínez Echeverría (2005): "Hay, en efecto, una dicotomía notoria entre las dos generaciones que se enfrentan: para los adultos, la mejor solución es el olvido, manteniendo así un orden ficticio que les da seguridad. Su discurso será el del silencio y se obligan a olvidar (como si eso fuese posible); sus hijas, en cambio, entienden que la solución no pasa por ahí y buscarán la forma de rescatar el pasado, apostando por la verdad aun cuando intuyen que aquello que se esconde puede ser muy doloroso (p. 69).

${ }^{6}$ El motivo del silencio de los adultos y sus consecuencias en la vida familiar reaparece y se enfatiza en el cuento Había una vez un pájaro (2013), donde la autora relee y reescribe su primera novela: "Mi madre me abraza fuerte, culposa, y yo pregunto qué pasa. Pero ella dice que no estamos en edad de entender, que paciencia, que algún día nos van a explicar todo (...) y vuelven unos días en que el silencio se vuelve una 
respecto de la actitud y conducta de su progenitora: "A mi madre el tema la deprime y eso es razón suficiente para no hablarlo" (Costamagna, 1996, p. 145). El dolor causado por el desconocimiento de lo sucedido y la consecuente pérdida de confianza en la familia, se sumará a la angustia de descubrir que lo sufrido por su padre había sido un exilio forzado, que él sí quería comunicarse con sus hijas durante ese tiempo en México, pero que ese derecho le fue negado por su esposa y su nueva pareja ${ }^{7}$.

La pérdida del padre, su suicido en México y la imposición del silencio respecto de la verdad de lo ocurrido, produce la destrucción de la familia y un descalabro libidinal que redunda en traiciones y conductas de signo negativo. Es así que la madre de Amanda se involucra con Lucas, íntimo amigo de su esposo, quien sentencia de manera elocuente: "A Lucas es al que odio. Primero se mariconea con la política y después con el amor. Flor de amigo" (p. 47). La degradación del grupo familiar y la crisis emocional se condensa en la figura de Berta, quien se relaciona sexualmente con un alumno del colegio donde enseña y se involucra al final con el padre de Amanda.

Por su parte, en La edad del perro de Leonardo Sanhueza, desde el inicio el tema del padre ausente se percibe como una latencia soterrada y acuciante. El narrador personaje comienza a sentir la urgencia de averiguar qué fue lo ocurrido con su progenitor y por qué no ha podido verlo en los últimos años. En un espacio familiar pinochetista y lleno de armas, donde hablar de la contingencia política está absolutamente prohibido, lo que prima es un silencio cómplice: "Ya sabía que mi papá había trabajado en la Base Manquehue, pero como hablar de mi papá es igual que hablar de política o religión, no tenía idea de que había trabajado con helicópteros" (Sanhueza, 2014, p. 57). El miedo generalizado y el silencio impuesto se hace extensivo al contexto de la ciudad de Temuco y por proyección metonímica a la realidad del país ${ }^{8}$.

Es lo que sucede en torno a la Editorial Quimantú y lo ocurrido allí con el padre: "Quimantú pertenecía al conjunto de palabras que las paredes logran escuchar con sus

sustancia espesa, casi masticable en el aire y no tenemos noticias de mi padre ni del tío Ramón ni de Lucas" (p. 34-35). Y más adelante: "Más me preocupa el silencio rotundo que nos acompaña; la manera en que empieza a fermentar y lo que puede ocurrir si alguien lo rompe" (p. 60).

${ }^{7}$ Según Elena Gómez Castro (2013), en los diversos estudios de la transmisión del trauma de una generación a otra (especialmente en el caso de los padres que vivieron una experiencia como el Holocausto y cuyo trauma se desplazó a la figura de sus hijos) se aprecian tres aspectos fundamentales, siendo el tercero el más pertinente para los efectos de entender el silencio presente en La edad del perro y En voz baja, esto es, el silencio al que fueron sometidos los hijos: "El tercer aspecto se refiere a la elaboración que realizan los niños con el conocimiento de lo que realmente les ocurrió a sus padres, lo cual tiene un papel preponderante cuando lo ocurrido se trata como un secreto familiar" (p. 74).

${ }^{8}$ Son pertinentes aquí los planteamientos de Nicoletti, Bozzolo y Siak (2005), en cuanto a lo que pasaba en tiempos de las dictaduras del cono sur, especialmente en Argentina (y Chile): "En el período dictatorial había un mandato de silencio, no se podía hablar, no se hablaba de los desparecidos. Los familiares se planteaban el riesgo que implicaba que los niños tuviesen información sobre el secuestro de sus padres, tanto por seguridad personal como por el posible rechazo del medio. En el caso de niños que preguntaban, el silenciamiento social se expresaba con frecuencia en otro sector social de la familia donde, por ejemplo, no había rastros del desaparecido, se quitaban las fotos, etcétera" (p. 63). 
oídos selectivos y que, por lo tanto conviene no decirlas" (p. 111). El desconocimiento de lo realmente sucedido con su padre y la imposibilidad de acceder a la verdad de lo ocurrido, obligarán al niño a establecer relaciones entre los hechos que han desaparecido del habla familiar: "Eso estaba fuera de mis cálculos. Los libros eran de la editorial Quimantú, pero no se me había ocurrido asociar eso con el golpe. Hay tantas cosas difusas, cosas que no se dicen, que solo se pueden averiguar por deducción, porque las paredes tienen oídos" (p. 110-111).

En este proceso de descubrimiento el niño protagonista se informará de que su padre, sargento de aviación, era contrario al golpe militar, que había sido acuartelado el 11 de septiembre y que se vio involucrado, de manera obligada, en el piquete que allanó la citada editorial. Los trabajadores fueron detenidos y llevados a la Academia de Guerra, donde fueron asesinados. Luego de dichos acontecimientos el padre fue enviado a Temuco, debido a su alcoholismo, y obligado a renunciar a los treinta y dos años.

El desplazamiento de la esfera individual a la colectiva se expresa en el conocimiento que el niño irá adquiriendo de la existencia en el país de detenidos desaparecidos, como es el caso de un amigo de su tía, quien señala: "El doctor Galdámez estuvo detenido en la Base Aérea de Manquehue, en el Grupo de Helicópteros (...) Conocimos a alguien que lo vio vivo allí, a fines del setenta y tres, comienzos del setentaicuatro. Ahí lo fusilaron" (p. 55-56).

La adquisición de conciencia de dicha realidad oculta signa al texto con una simbología tanática donde todo es contaminado por signos de desaparición y muerte. Se impone así una visión de mundo apocalíptica cuya tesitura alcanza desde la mente del narrador a los signos de la naturaleza.

Es importante destacar que el discurso del narrador deja al descubierto las marcas textuales que evidencian la dificultad de hacer memoria y de acceder en dicho proceso a la verdad de lo sucedido. El narrador niño está consciente no solo de la confusión que lo afecta, sino también de que la reconstrucción de los hechos que le han silenciado implica una ardua tarea de interpretación y reinterpretación. Por ello considera que al pasado "lo ha ido reconstruyendo con elementos muy precarios, piezas sueltas que he logrado atrapar al vuelo. Por lo mismo, por falta de datos y matices, reconozco que me he pintado esa prehistoria como un cuento de hadas" (p. 58).

\section{SENSIBILIDAD APOCALÍPTICA Y CANCELACIÓN DE UNA IMAGEN DE FUTURO}

En la novela de Alejandra Costamagna (1996), el sustrato apocalíptico se focaliza y condensa en el cuerpo auto-vejado de la protagonista. La búsqueda infructuosa del padre, la mentira generalizada, el silencio de los miembros de la familia y el desastre de los vínculos afectivos tiene como consecuencia en Amanda el deseo de autoaniquilación. Ello se traduce en su negativa explícita a seguir alimentándose, síntoma este del rechazo a todo lo que la rodea: "Por eso los desayunos comenzaron a asquearme y, en rigor, comenzó a asquearme la comida, la gente, la vida social. De pronto quería vomitarlo todo" (p. 56). El cuerpo como territorio de la automutilación escenifica su proceso de 
deterioro: "Con el cuerpo color morado miré lo delgada que me encontraba" (p. 171). Al mismo tiempo, el deseo de no alimentarse se une a la negativa a experimentar el cuerpo como un ámbito erotizado y sexuado: "No estoy declarando que sea lesbiana. Solo que el sexo no me provocaba ninguna curiosidad. Incluso me daba un poco de asco recordar los lengüetazos del amigo de Camila" (p. 152).

El cuerpo negado hablará sin embargo desde esa negación y pulsión de muerte mediante el deseo de morir que comienza a hacerse explícito en el discurso de Amanda, deseo que se acentúa al constatar que la separaron arbitrariamente del padre, le silenciaron la verdad de su paradero y no la informaron de que este había fallecido: "Mi padre estaba muerto y ya nada me importaba mucho" (p. 168). La falta de sentido para seguir viviendo la lleva a querer desaparecer y cortar la comunicación con el mundo. Una vez que vuelva de México del funeral de su padre su deseo de morir cerrará el curso de la historia narrada y marcará el fin de la: "Después me moriría un poco en cámara lenta y ya no hablaría más" (p. 173).

En lo que respecta a La edad del perro, el estado de ánimo del texto se expresa en la tonalidad apocalíptica que cruza la novela y se despliega desde la conciencia del niño narrador y protagonista. En un primer momento se enfatiza la influencia de la abuela adventista en la interiorización de la idea de un fin de mundo que está próximo: "Estoy pensando que, a menos que otra fatalidad anticipe el desenlace, voy a morirme a los veintiséis años, algún día del dos mil, cuando se mueran todos, carbonizados bajo una lluvia de estrellas" (p. 14-15). Sin embargo, más adelante se advierte que la percepción apocalíptica se nutre igualmente de condiciones contextuales donde la experiencia de la dictadura y lo vivido por el niño son responsables de dicha concepción de mundo. Orientando el pulso de la enunciación y al modo de un leitmotiv musical, la reiteración de frases-tema, tales como "cuando todo se acaba para siempre" (...) "El apocalipsis está delante como un murallón" (p. 15), escenifican una imaginación terminal que se expone en núcleos temáticos como es el caso del juego preferido del niño, esto es, el construir con maderos una ciudad en guerra y bombardeada: "una ciudad prehistórica o postapocalíptica, las casas no eran casas, sino cueva o túneles ciegos, con entradas forzadas con palitos" (p. 68). El juego deviene metáfora de un mundo donde abundan situaciones límites que auguran un desastre inminente: "Erupciones volcánicas, epidemias, hambruna, terremotos, bombardeos, granizos del porte de un puño (...) el fantasma de la guerra con Argentina" (p. 16-17).

Al desplegar el contexto de destrucción que observa a su alrededor, en una ciudad donde los roedores convierten la casa en cartón y devoran toda materia "día y noche, incansablemente" (p. 72), el niño narrador se pone a resguardo de las eventuales percepciones que puedan interpretar su relato como proyecciones de una imaginación febril o abiertamente dislocada: "De modo que la sensación de desastre inminente no es algo fantasioso, no, no son ideas mías, sino que se irradia soterradamente y sale de vez en cuando" (p. 17). 


\section{CONCLUSIONES}

Como se ha podido apreciar, los temas de la memoria, del duelo inacabado, del estado de ánimo apocalíptico predominante en estas novelas, evidencian la persistencia de un imaginario que se resiste a ser neutralizado por nuevos derroteros de significación. En vez de ello la activación del sustrato apocalíptico en el espesor narrativo y el estado de ánimo de desesperanza predominante, deviene núcleo temático decisivo para intentar entender ese algo difuso, pero denso, que ha determinado parte del imaginario social y literario de estos últimos años. En el caso de En voz baja de Alejandra Costamagna y La edad del perro de Leonardo Sanhueza, la sensibilidad apocalíptica se ha concentrado en la infancia de narradores niños, etapa de sus vidas que ha sido interferida por los avatares del horror de la dictadura y por una imaginación que parece clausurar nuevas alternativas de futuro.

\section{OBRAS CITADAS}

Amaro, Lorena (2014). "Parquecitos de la memoria: diez años de la narrativa chilena". Revista Dossier 26: 35-42.

Baczko, Brosilaw (1984). Los imaginarios sociales. Memorias y esperanzas colectivas. Buenos Aires: Ediciones Nueva Visión.

Borradori, Giovanna (2004). La filosofia en una época de terror-Diálogos (de Giovanna Borradori) con Jurgen Habermas y Jacques Derrida. Buenos Aires: Taurus.

Bottinelli, Alejandra (2016). "Narrar (en) la Post: la escritura de Álvaro Bisama, Alejandra Costamagna, Alejandro Zambra". Revista Chilena de Literatura 92: 7-31.

Butler, Judith (2006). Vida precaria. El poder del duelo y la violencia. Buenos Aires: Paidós.

Carreño, Rubí (2009). Memorias del nuevo siglo: jóvenes, trabajadores y artistas en la novela chilena reciente. Santiago: Cuarto Propio.

Costamagna, Alejandra (2013). Había una vez en verano. Santiago: Editorial Cuneta. (1996). En voz baja. Santiago: LOM.

Freud, Sigmund (1978). "Duelo y melancolía", en Obras Completas, Buenos Aires: Amorrortu, Tomo XIV: 235-255.

Gómez Castro, Elena (2013). Trauma relacional temprano. Hijos de personas afectadas por traumatización de origen político. Santiago: Ediciones Universidad Alberto Hurtado.

Gumbrecht, Hans Ulrich (2011). Stimmungen / Estados de ánimo. Sobre una ontología de la literatura. Murcia: Tres Fronteras ediciones.

Jeftanovich, Andrea (2012). Hablan lo hijos. Discursos y estéticas de la perspectiva infantil en la literatura contemporánea. Santiago: Cuarto Propio.

Jelin, Elizabeth (2002). Los trabajos de la memoria. Madrid: Siglo XXI. 
Llanos, Bernardita (2013). "La espacialización de la memoria en Nona Fernández y Carmen Castillo". Chile urbano: la ciudad en la literatura y el cine. Santiago: Cuarto Propio.

Martínez, Claudia (2005). "La memoria silenciada. La historia familiar en los relatos de tres escritoras chilenas: Costamagna, Maturana y Fernández". Taller de Letras 37: 67-76.

Moulian, Tomás (2010). El deseo de otro Chile. Santiago. Santiago: LOM.

Nicoletti, Elena, Raquel C. Bozzolo y Daniela Siaki (2005). "Infancia y represión política", en Diana Kordon, Lucila Edelman, Darío Lagos y Daniel Kersner (eds.). Efectos psicológicos y sicosociales de la represión política y la impunidad. De la dictadura a la actualidad. Buenos Aires: Asociación Madres de Plaza de Mayo: 62-69.

Peñaloza, Carla (2015). El camino de la memoria. Santiago: Editorial Cuarto Propio.

Rojas, Sergio (2015). "Profunda superficie: memoria de lo cotidiano en la literatura chilena". Revista Chilena de Literatura 89: 231-256.

Sanhueza, Leonardo (2014). La edad del perro. Santiago: Random House Mondadori.

Sherpe, Klaus (1987). "Dramatization and De-dramatization of the End: the apocalyptic consciousness of modernity and post-modernity", Cultural Critique 5 (19861987): 95-129. 